Maxwell, C. (2007) “Alternative' narratives of young people's heterosexual experiences in the UK', Sexualities, 10(5): 539-558.

\title{
'Alternative' narratives of young people's heterosexual experiences in the $\mathrm{UK}$
}

Claire Maxwell 
Maxwell, C. (2007) “Alternative' narratives of young people's heterosexual experiences in the UK', Sexualities, 10(5): 539-558.

\begin{abstract}
Thirty-eight young men and women from contrasting social locations were interviewed in-depth about their sexual relationships, with a focus on gender roles and attitudes, romantic relationship expectations and sexual experiences. Analysis of young people's narratives revealed that these moved relatively easily between 'normative' and 'alternative' frameworks when situating and accounting for attitudes and heterosexual practices. Despite some evidence for the existence of 'non-hegemonic' narratives, young people often reverted back to more normative models of heterosexual experience and expectations. Gender and prior negative (childhood) experiences appeared to influence young people's ideas about and expressions of 'alternative' identities and practices while, within the context of this small-scale study, the impact of socioeconomic status seemed relatively insignificant.
\end{abstract}

Keywords: young people, heterosexuality, gender, resistance, socio-economic status 
Maxwell, C. (2007) “Alternative' narratives of young people's heterosexual experiences in the UK', Sexualities, 10(5): 539-558.

\section{'Alternative' narratives of young people's heterosexual experiences in}

\section{the UK}

\section{Introduction}

Increasingly, research into young people's heterosexual identities and practices suggests these often draw upon and utilise contradictory discourses (O'Donnell and Sharpe, 2000), appear to be relatively 'fluid' in nature (Stewart, 1999; Allen, 2005), and demonstrate variable levels of resistance and accommodation to 'traditional' (Allen, 2003) heterosexual gender role interactions, as defined for example by Holland et al.'s 'male in the head' model (1998) [1]. This emerging research suggests that despite evidence of continued adherence to 'dominant discourses of heterosexuality' (Allen, 2003: 215), there is data indicating that young women can be 'assertive' and active subjects during sexual experiences (Stewart, 1999, Jackson and Cram, 2003; Wilkins, 2004; Allen, 2005; Maxwell, 2006a), and revealing that young men pursue emotionally connected rather than purely instrumental sexual relationships (Allen, 2003, Tolman et al., 2004; Korobov and Thorne, 2006; Maxwell, 2006b).

Evidence of new or changing heterosexual attitudes and practices among young women can be found in studies undertaken in a number of countries. Stewart (1999), for example, has argued that one third of her sample of 20 Australian young women was engaged in a 'transition discourse', whereby young women displayed critical consideration of their relationships with men and the development of more assertive and/or alternative heterosexual femininities. Young women were said to be 'reworking' 
Maxwell, C. (2007) “Alternative' narratives of young people's heterosexual experiences in the UK', Sexualities, 10(5): 539-558.

the 'givens' of heterosexual practice (Stewart, 1999: 275), such as initiating sex, stating conditional terms for relationships with men, participating in casual sex, making efforts to ensure their own sexual pleasure and so forth.

In her work in New Zealand, Allen (2003) has reported that some young women interviewed were aware of and challenged what Lees called the 'double standard of sexual morality' (1986:25), recognised female sexual desire as 'normal' (Allen, 2003: 222), and positioned themselves as relatively active subjects in their sexual encounters. Other studies have also pointed to emerging alternative gender scripts and heterosexual practices (Harris et al., 2000; Schippers, 2000; Shefer and Foster, 2001; Jackson and Cram, 2003; Ortiz-Torres et al., 2003; Youdell, 2005).

Research specifically focusing on men and their heterosexual identities and practices has grown rapidly over the past decade. In a study of 44 young British men from white, African-Caribbean and Asian backgrounds, O'Donnell and Sharpe (2000) found that some of the young men interviewed seemed 'mixed up' (p. 89), in that they appeared to be combining traditional and non-traditional gender traits in the expression of their self understandings and heterosexual expectations and experiences. Other recent studies have reported that young men not infrequently discuss their interest in romantic, emotionally involved relationships with young women (Breakwell and Millward, 1997; Allen, 2003; Seal and Ehrhardt, 2003; Korobov and Thorne. 2006).

Frosh et al. (2002) identified young men in their study, which was also carried out in the UK, who actively attempted to set themselves apart from the norm of 'hegemonic masculinity' (Connell, 1995) [2] by portraying themselves as autonomous from their peers and sensitive to the needs of women. Redman's (2001) study of young men studying for GCE 'A' Levels (one of the highest qualifications available in English 
Maxwell, C. (2007) “Alternative' narratives of young people's heterosexual experiences in the UK', Sexualities, 10(5): 539-558.

secondary schools) at a sixth form college found young men who had invested in a white, middle-class heterosexual identity as the 'romantic hero' (p. 195), which reflected the individualised, competitive environment they inhabited for their education, as well as an attempt to distance themselves from working-class masculine identities.

Influenced by Foucault and post-structuralism, much of this recent research suggests the possibility of 'resistance' to dominant gender and sexual ideologies is always present. The literature is now replete with a range of terms (transition - Stewart, 1999; reinscription and subversion - Schippers, 2000; resistance - Allen, 2003; Jackson and Cram, 2003; sexual agency - Wilkins, 2004; performative resignification and discursive agency - Youdell, 2004), which are used to describe examples of heterosexual practices that are seen as oppositional to so-called 'traditional' (Allen, 2003), 'dominant' (Jackson and Cram, 2003; Allen, 2005), 'hegemonic' or 'normative' (Stewart, 1999) frameworks of gender interactions. While categorising young people's narratives and experiences in these kinds of ways can arguably lead to the creation of a static representation of heterosexual identities which are thought to have existed in some past era, as well as a somewhat uncritical grouping of all 'alternative' (Jackson and Cram, 2003) narratives and practices together, the strength of this literature has been to demonstrate how youthful heterosexual positionings are constantly in movement between discourses.

Despite examples from research on young people's practices and identities that offer 'hope' (The London Feminist Salon Collective, 2004) by challenging 'dominant discourses of heterosexuality' (Allen, 2003), the extent and nature of any sustained change in heterosexual experiences remains uncertain. Terms such as 'transition' (Stewart, 1999) could be seen to suggest that young women are gradually moving 
Maxwell, C. (2007) “Alternative' narratives of young people's heterosexual experiences in the UK', Sexualities, 10(5): 539-558.

towards something new (and, by implication, improved). Yet other research into femininities shows that 'traditional normative prescriptions' (Harris et al., 2000: 386) continue to dominate (Shefer and Foster, 2001; Jackson and Cram, 2003; Ortiz-Torres et al., 2003; Maxwell, 2006a). Jackson and Cram (2003), for example, found that young women's resistance was 'tenuous and fragile' (p. 123) and Allen (2003, 2005) concluded that the young women (and men) in her study were simultaneously accommodating and resisting dominant forms of heterosexuality.

Changes in masculine heterosexual identities and expectations are described by some as showing something of a tension between 'old' and 'new' versions of masculinity, whereby men display both 'a thin, contemptuous misogyny in which women are treated basically as disposable receptacles for semen, [which] coexists with a much more respectful, even admiring view of women's strength...sometimes these views coexist in the same head' (Connell, 1995: 108). All researchers seem to agree that despite the multiplicity of self understandings and identities adopted, the development of new expressions of masculinity and heterosexual expectations do not necessarily challenge or resist traditional gendered power relations (Cornwall and Lindisfarne, 1994; Wetherell and Edley, 1999).

The extent and nature of any change in young men and women's roles and practices within heterosexual relationships varies between studies undertaken with different groups of young people. Research has identified a range of factors that might explain the variations found. Socio-economic class appears to influence gender roles assumed (Hey, 1997; O’Donnell and Sharpe, 2000; Redman, 2001; Walkerdine et al., 2001; Frosh et al., 2002; Youdell, 2005) and the different economies of value attached to heterosexual identities (Thomson, 2000). Ethnicity and cultural location also seems to 
Maxwell, C. (2007) “Alternative' narratives of young people's heterosexual experiences in the UK', Sexualities, 10(5): 539-558.

influence young people's expression of sexuality (Mac an Ghaill, 1994; O’Donnell and Sharpe, 2000; Frosh et al., 2002; Weekes, 2002, Youdell, 2005), as does age which has been found to affect gender identity development (Gilligan, 1995) as well as the extent to which gender identity is aligned to peer group norms (Walker and Kushner, 1999 and Wight, 1999). Significantly, however, heterosexual identities and practices are influenced not only by structural factors such as socio-economic status, but also by contextual factors, such as the settings in which these identities are being expressed (in school - Youdell, 2005; in an 'alternative sub-culture' - Schippers, 2000; Wilkins, 2004; in a focus group discussion - Allen, 2005; or within an intimate conversation or relationship - Korobov and Thorne, 2006).

Findings such as those highlighted above point to the need for closer examination of the degree to which young men and women draw on 'traditional' and 'non-traditional' frameworks of understanding, and the factors which may explain the various positionings young people take up in relation to (hetero)sexuality. This paper offers an in-depth exploration of young people's narratives, examining whether different discourses are used when discussing various dimensions of sexual and intimate relationships such as gender roles, relationship expectations, sexual pleasure, coercive experiences. Furthermore, by drawing on data from a study of young people occupying a variety of social locations, the paper includes a critical examination of whether, and how, contextual and structural factors act to disrupt so-called 'traditional' heterosexual identities and practices. 
Maxwell, C. (2007) “Alternative' narratives of young people's heterosexual experiences in the UK', Sexualities, 10(5): 539-558.

\section{The research: sample and methods}

As part of a larger study exploring young men and women's experiences of sexual relationships, thirty-eight young people (of whom 22 were young women), ranging in age from 16 to 23 years, were approached to participate in in-depth interviews. Young people were recruited from a broad range of social locations, which differed by socioeconomic status and type of current living situation, in order to facilitate an exploration of how contextual and structural factors influenced heterosexual identities and practices. In order to maximise effects linked to social location, one group (22 young people) was recruited from a young offenders' institution and two supported accommodation units (where young people who had experience of homelessness, living independently from age 16, serious substance misuse problems, and/or teenage parenthood were provided with accommodation and 24-hour a day support) [denoted in this paper by G1]. The second group of young people were selected from two fee-paying boarding schools in the same medium-sized UK city, where young people were studying for their GCE ' $\mathrm{A}$ ' Levels [denoted in this paper by G2].

During the interview, young people were asked to describe two or three recent or 'significant' (Wight and West 1999, Hollway and Jefferson 2000) sexual relationship experiences. Young people from both groups talked of a range of relationship and sexual experiences during the interviews, discussing both specific experiences with another person (often in considerable detail - how they met, how they spent time together, experiences of conflict, their sexual relationship development), and more general attitudes and perceptions about gender roles and the place sexual relationships held in their lives. A number of young people commented at the end of the interview 


\section{Maxwell, C. (2007) “Alternative' narratives of young people's heterosexual experiences in the UK', Sexualities, 10(5): 539-558.}

that they had enjoyed the opportunity to talk about their intimate experiences and assess these in relation to other relationships or sexual encounters they had had.

Not surprisingly, where young people were currently involved in a romantic relationship, they tended to be less critical of these than the past experiences they talked about. However, the relatively 'safe' environment (c.f. Allen, 2003) provided by the interview, allowed most young people to discuss current relationship concerns, mull over unresolved emotions that had resulted from a relationship breakdown, or position their aspirations for sexual relationships in relation to their current situation (for instance, being incarcerated, trying to 'beat' their heroin habit, preparing for GCE 'A' Level exams).

The interview process of discussing two to three sexual and/or relationship experiences in-depth, and situating these on a timeline from first sexual experience to the present, helped to create a brief life history for each participant from ages 13-14 to the present. These were used as case studies to explore how experiences and attitudes were reported to have changed over time, to highlight variability, 'fluidity' (Stewart, 1999) and contradictions within a young person's narrative, and investigate how contextual factors had influenced discourses and practices.

Interviews were tape-recorded and transcribed verbatim. Using a mixture of open and axial coding (Neuman, 2000), a thematic analysis of the data was conducted and differences between young people's attitudes and experiences of sexual relationships noted. A case study analysis was then conducted to explore more individualised approaches to heterosexual identities and experiences.

As the current study aimed to build on the work of researchers such as Allen (2003) and Stewart (1999) previously published in this journal, data were analysed 
Maxwell, C. (2007) “Alternative' narratives of young people's heterosexual experiences in the UK', Sexualities, 10(5): 539-558.

using similar definitions to those adopted by the two authors. Thus, 'dominant' and 'traditional' heterosexual identities and practices were defined by the nature of the subject position most usually taken up by young men (active subject) and women (passive object) within the accounts.

This paper will initially report on the overall findings of the study in terms of the nature of young people's narratives of heterosexual relationships and the extent to which they suggest changing or 'alternative' discourses. The way in which young men and women discuss their views and experiences across various dimensions of sexual and intimate relationships will be analysed, as will be the question as to whether participants' social location appears to influence their narratives.

Four short case studies will then be introduced of two young women and two young men from different social backgrounds. These case studies illustrate in depth some of the elements of movement and contradictions found among the wider sample's heterosexual attitudes and practices, but also help to reveal how contextual and structural factors may influence the expression of resistant or alternative narratives of participants' sexuality and heterosexual practices. Given the acknowledged influence of the research environment on young people's narratives (Schippers, 2000; Allen, 2005; Youdell, 2005; Korobov and Thorne, 2006), each case study is prefaced by a short description of the context in which they were interviewed. 
Maxwell, C. (2007) “Alternative' narratives of young people's heterosexual experiences in the UK', Sexualities, 10(5): 539-558.

\section{Young people's narratives concerning sexual relationships}

Young people expressed a variety of heterosexual attitudes and experiences, many moved relatively easily between expressing what other studies would categorise as 'non-traditional' attitudes while at the same time describing and making sense of their experiences using what might be described as the 'dominant' heterosexual framework of understanding. This often resulted in seemingly contradictory narratives, where ultimately any clear shift away from 'normative' heterosexual identities and practices seemed tenuous.

The disjunction between espoused gender roles, romantic relationship expectations and actual relationship experiences

Many young people's descriptions of sexual relationships conformed to what might be described as traditional heterosexual norms. The majority of young women and men when discussing gender attributes and roles emphasised that women fell into two categories: 'slags' (Jamie, G1) or 'decent girls' (Kim, G1). On the whole, young women held negative attitudes towards 'one-night stands' (Shelley, G2), and young men, while the majority engaged in such sexual encounters, strongly supported the idea that women who were sexually motivated and adopted active subject positions in their interactions with men, or who would 'let off [sex] easy' (Len, G1), could never become their 'girlfriends' (Len, G1).

Most young men, especially those in the young offenders' institution, felt under pressure to cultivate a 'reputation' (Jesse, G1). Reputations were maintained by having a long scorecard of sexual conquests, the 'main word travel[ling]' (Dylan, G1), via 
Maxwell, C. (2007) “Alternative' narratives of young people's heterosexual experiences in the UK', Sexualities, 10(5): 539-558.

previous female sexual partners, throughout a neighbourhood that the young man in question had successfully performed (sexually), and being able to boast to a peer group how quickly they managed to 'put away [have sex with] a girl' (Taylor, G1).

Evidence for adherence to the traditional gender roles within sexual encounters reported in other research was also to be found in the descriptions provided by participants in this study: most young men felt they had to initiate and drive a sexual encounter, while young women played the role of the gatekeeper, whose role was to consent or resist progression from one stage of the encounter to the next.

On the other hand, when reflecting on romantic relationships (as opposed to more casual relationships or sexual encounters), especially those discussed and aspired to at the time of the interview when the average age of the participants was 18 years, young men in particular demonstrated a commitment to a set of expectations that could be seen as more gender equal. Many young men and almost all young women wanted a partner who would 'be there for you' (Lucy, G1), with whom you could 'be yourself' (Darrell, G1), whom you could 'simply trust' (Lindsey, G2) and be 'deep friends' (Lea, G2) with.

In their descriptions of relationships they aspired to, young men also discussed a need for 'someone... who actually understands where I am coming from, because I have got a lot of traumatic stuff to deal with, and...somebody...that can relate to you' (Darrell, G1). Such narratives portrayed young men as having emotional, not just sexual, needs and projected onto their female partners a significant personalised and active function, not apparent in their objectifying statements made about women more generally. 
Maxwell, C. (2007) “Alternative' narratives of young people's heterosexual experiences in the UK', Sexualities, 10(5): 539-558.

Many young women also described pursuing more active roles within these more emotionally connected romantic relationships, in which they invested energy and commitment to supporting their partner to change and/or reach their potential, as illustrated for example by this young woman Lucy $(\mathrm{G} 1)$ :

Before I got with [my boyfriend] he was a mess, he was on the dole, smoking dope every day...I said to him, "Listen, if you and me are going to be together, [have a] future...you need to get up, get a job and that", then about a month [later], suddenly he turned around, [but] it took a long time...

Despite the presence of 'alternative' descriptions of romantic relationship aspirations and, in some cases, romantic relationship experiences, a number of overarching themes pervaded young people's narratives of actual romantic relationships, which set them firmly back into a model of 'traditional' heterosexual practices. These included possessive male behaviour ('I just got insanely jealous because...for example today...someone sat on her lap and I was like what?!' - Pete, G2); strongly gender differentiated expectations of fidelity ('I know I can trust her, but she [can only] hope [that] she can trust me' - Warren, G1); and threatened and actual physical violence:

He gets really jealous, because he can see me talking to people and he feels angry inside I think...one night [we just had] this stupid row...[and] he grabbed me... and basically shook me and his face just 
Maxwell, C. (2007) “Alternative' narratives of young people's heterosexual experiences in the UK', Sexualities, 10(5): 539-558.

changed, it wasn't like a face you know "I love you", it was [a] "I hate you" face (Rachel, G2).

All the young women sampled from the supported accommodation units, and the vast majority of young women recruited from fee-paying boarding schools, detailed experiences that had one or more of these dimensions to them. Young men, especially those recruited through the young offenders' institution and supported accommodation unit (G1), also discussed having displayed such forms of behaviour.

These findings suggest that many of the young men in this study were able to adopt non-traditional subject positions within certain areas of their sexual and intimate relationships (e.g. with respect to expectations of romantic relationship) more easily than in others, such as the initiation of sexual encounters, but that these 'alternative' narratives were not usually sustained or actualised when describing actual relationship experiences. Socio-economic location did not appear to significantly differentiate the narratives of young people across the various dimensions of sexual and intimate relationships (a more detailed examination of this in relation to young women is available in Maxwell, 2006a).

The contradiction and movement between the subject positions ascribed to in young people's romantic relationship aspirations and their lived experiences, was also in evidence across two further areas of participants' narratives - young men discussing femininities and young women's experiences of sex. Again, while socio-economic position seemed unrelated to the discourse adopted by young people, gender appeared to be more significant. 
Maxwell, C. (2007) “Alternative' narratives of young people's heterosexual experiences in the UK', Sexualities, 10(5): 539-558.

Young men discussing young women in contradictory voices

While young men's abstract gender attitudes, described earlier in the paper, did soften when they discussed young women with whom they were romantically involved, even during these narratives, most young men continued to draw on negative, 'stereotypical' attitudes of women. Such a disjuncture was evident during Dylan's (G1) interview. Dylan often objectified women ('I didn't really want that (meaning girl) in my bedroom after I gave it the sex, it's rubbish') and portrayed himself as hard, independent and 'highly sexed'. However, when discussing his current relationship, this same respondent drew on a range of often contradictory voices:

There ain't nothing in the world I wouldn't do for her [his girlfriend];... [but] she will never find out about what I do [having sex with other women]...[even] if she knew I did it, she still wouldn't leave me...because I make her feel good about herself.

It seemed as if Dylan felt unable to move too far away from framing his emotions and experiences within the traditional heterosexual framework, and any deviation from this was swiftly followed by a period of re-establishing himself firmly within such a model. Such retreats back to a traditional model could be found at numerous points in his narrative. 
Maxwell, C. (2007) “Alternative' narratives of young people's heterosexual experiences in the UK', Sexualities, 10(5): 539-558.

Young women negotiating between sexual pleasure and pressure

A second area in which the development of an alternative discourse seemed to occur, but remained tenuous and unstable, this time among young women, concerned the experience of sexual pleasure and sexual pressure within the same relationship. Sarah (G1) talked of such an experience within her current relationship. She appeared to have a satisfying sexual relationship with her partner, demonstrated by comments such as this one:

Interviewer So had you had orgasms before having slept with [current boyfriend]?

Sarah Yeah, manually, myself, not by anyone else...so that was like a huge surprise.

At the same time, however, she described an 'agreement' she had with her partner:

When I am on my period especially...we won't have sex anyway and you know that's like the agreement...but he [boyfriend], you know, he still wants a blow job.

From the tone of her voice during this section of the interview, Sarah appeared to be intimating that she was uncomfortable with, and frustrated by this arrangement. Sarah's experience illustrates how sexual pleasure and pressure can co-exist within a sexual relationship. 
Maxwell, C. (2007) “Alternative' narratives of young people's heterosexual experiences in the UK', Sexualities, 10(5): 539-558.

As in some previous studies, young people's narratives of their sexual relationship expectations and practices demonstrated variability and contradiction both across the groups that were sampled and within individual's narratives. Although such findings are not new, this study does contribute to our examination of the extent of the shift observed in attitudes and practices across the various dimensions of sexual and romantic relationships, and among very different groups of young people. The following four short case studies help to further illustrate something of the variability found within individual narratives, as well as allowing a more detailed exploration of contextual factors that facilitate or hinder the emergence of 'resistant' or 'alternative' attitudes and practices.

\section{Similarities and contradictions in young women's narratives across social location}

Chrissie and Sarah were two young women occupying very different social locations at the time of the interview. In their accounts of their sexual relationship experiences, they seemed to draw relatively heavily on 'non-traditional' gender roles and experiences, as did a large minority of the other young women interviewed. Nevertheless, Chrissie and Sarah would regularly revert back to more hegemonic norms to explain some of their choices or aspirations. This resulted in some striking contradictions in their narratives, which they rarely seemed to recognise.

Chrissie was 17 years-old at the time of the interview. She had had a variety of relationship experiences (a better description might be heterosexual encounters), but had not yet had sexual intercourse. Chrissie seemed to speak without much inhibition during the interview as she described a number of experiences that many adults would have judged as shocking and dangerous, and discussed in some detail her difficult family 
Maxwell, C. (2007) “Alternative' narratives of young people's heterosexual experiences in the UK', Sexualities, 10(5): 539-558.

history. She seemed comfortable in her surroundings and talking to the female researcher who was of a similar ethnicity and class background.

Chrissie cultivated an image of herself, likely to have been supported by her middle-class background (Youdell, 2005; Kehily and Pattman, 2006), as 'arty', liberal and experimental, both in terms of her clothing, her career ambitions and her attitude to her emerging sexuality. During the first part of the interview, Chrissie described a number of sexual experiences that seemed to suggest she was committed to nontraditional gender roles and experiences. The first experience she described during the interview was how she had met a slightly older American artist on a plane journey. They kept in touch via e-mails and would then meet up when he came to the UK. Chrissie and this man would usually go to the cinema where they would kiss and pet. He would ask her to come back to his hotel room with him, but she declined because 'there is no way I could actually get help [once in the hotel room].....I did trust him really...but at the same time it would be like stupid so...'.

Chrissie then told how she had met a soldier one evening in town and agreed to meet up with him the next day. They went to the cinema and petted, followed by a walk along the canal where 'I think he like basically expected me to have sex with him, up against a fence... so I basically ran away...'. Chrissie described being fully aware of the potential risk she was placing herself in, but her ultimate reflection on these risky situations was 'you can say, I should never had done that, but...it's not so bad, nothing happened...I'm young, I'm still here and I'm still fine...you need to experience [things], otherwise you don't know... [you won't get any] pearls of wisdom'.

The risky situations Chrissie seemed actively to seek out stood in marked contrast to comments she made about her aspirations for losing her virginity or having a 
Maxwell, C. (2007) “Alternative' narratives of young people's heterosexual experiences in the UK', Sexualities, 10(5): 539-558.

long-term, committed relationship. Chrissie discussed wanting to lose her virginity only if 'I...feel so comfortable with that person...I just don't see the point in doing it [having sex] for the hell of it...I really want to reach an understanding, and respect them...know what they want and feel really comfortable with them'. This represented a relatively traditional view of the circumstances in which a young woman might be willing to experience intercourse for the first time.

Chrissie also described a desire for long-term relationship once she finished secondary school and went to university, where she thought she would meet people who were similar to her. Despite such aspirations, Chrissie had on several occasions actively created situations where she was alone with men who did not have the same 'common experiences' as her and where presumably the men had expected sexual intercourse would take place.

Sarah was 23 years-old at the time of the interview and living in supported accommodation. She had participated in a mixed-sex focus group (which formed part of the wider study this paper stems from), prior to the interview, which had been facilitated by the same researcher. Like Chrissie, she was very open about her experiences, discussing in detail her current relationship, her anxieties about it, her strong feelings for her partner, and their sex life. Sarah had undergone several years of therapy as a result of experiencing childhood sexual abuse, which could in part explain some of the reflexivity she demonstrated during her interview.

Sarah's account of her sexual experiences during her teenage years stood out from those of her peers in the same sample, because she had only lost her virginity at age 16, much later than others, and because she had made an active choice to do so: 'basically I knew I wanted to lose my virginity when I went on holiday and I did it...no 


\section{Maxwell, C. (2007) “Alternative' narratives of young people's heterosexual experiences in the UK', Sexualities, 10(5): 539-558.}

more beating about the bush. I thought I'd find someone that I like and I'll do it'. From the ages of 16 to 22 Sarah had not had any long-term relationship experiences, but had engaged in sex with men she usually met when she was out socialising. This had led to a number of sexual encounters in which she had either been unable to consent due to having drunk too much alcohol, or where Sarah had not wanted to have penetrative sex but had felt she had 'led [the man] on' (Lees, 1986: 20) by agreeing to go back to his house, or because she had started to become physically intimate with him: '[sex] had started and I couldn't say stop because it had already started...[so] you just lie there...you don't say anything'.

Sarah had felt strongly she had not been ready to have a relationship due to her experiences of childhood sexual abuse, and like Chrissie, evaluated her experiences during this time of her life as self-driven and valuable. While Sarah seemed to have pursued a relatively non-traditional sexual relationship pathway through her teenage years, and said she had set out to have 'sex for my own needs' during these encounters, the experiences she described seemed on the whole out of her control and unwanted.

Recently, Sarah had embarked on a relationship which she assessed overall as being loving and committed. However, while discussing this current relationship, she also described a number of negative experiences and emotions (sexual pressure, violent behaviour by her boyfriend, intense jealousy of her boyfriend's relationship with his expartner) that stood in stark contrast to such a positive description. One example of such a contradiction was that while her boyfriend was the first man with whom Sarah had had an orgasm, arguably a sign of a sexually fulfilling relationship, she also described feeling under pressure to have sex with him on a daily basis. Sarah described how one night, 
Maxwell, C. (2007) “Alternative' narratives of young people's heterosexual experiences in the UK', Sexualities, 10(5): 539-558.

[I] thought I'd test him by saying no, just because I wanted to say no', which her boyfriend seemed to accept, and they had just had a cuddle and went to sleep. On 'the next night, [I said] "No, I don't want to" [have sex], I could tell that it was sort of like he couldn't understand, he wanted to ask me why but he didn't and he just sort of like got in a little bit of a mood and just went to sleep...[then] the next night I didn't try [to say no] because I was scared [because] I didn't know what would happen.

Chrissie and Sarah's case studies illustrate two of the key points made earlier about the young women's narratives on the whole: namely vacillation between sexual pleasure or experimentation experiences and coercive interactions, and a disjuncture between expectations or assessments of relationships and actual experiences. Both Chrissie and Sarah appeared, at least partially, to be two young women who were active agents in their relationship choices, and especially around the age of 16, portrayed themselves as more interested in pursuing sexual rather than romantic relationships. Chrissie suggested her youth entitled and required her to experiment sexually, while her middle-class background offered her a 'liberal' identity that supported and made this acceptable. Sarah, also comfortable with recounting sexual experiences with men she did not know well, did not draw an association between her experiences and her social location in the same way as Chrissie did, but seemed to suggest that having been sexually abused as a child had provided her with the mettle to make an active choice not to embark on a committed or long-term heterosexual relationship. Both young women 
Maxwell, C. (2007) “Alternative' narratives of young people's heterosexual experiences in the UK', Sexualities, 10(5): 539-558.

also linked their age to the choices they made - for instance, Chrissie decided to wait until she began university to embark on a long-term relationship, and Sarah wanted to experience non-committed sexual encounters rather than a committed relationship due to her experiences of childhood abuse.

Despite such narratives of resistance to normative gender roles, both young women continued to draw on traditional models of understanding as well, for instance when Sarah discussed why she had not challenged situations in which unwanted sex had occurred or when Chrissie explained why she put herself in risky situations with older men (because she received a 'confidence boost' when older men showed an interest in her). Perhaps these young women, while open to cultivating and experiencing alternative identities and heterosexual practices, did not expect the men they interacted with to move away from a normative heterosexual model. This may explain why Chrissie and Sarah integrated their narratives almost seamlessly back into such a 'traditional' framework when their aspirations were not successfully translated into practice.

Young men's contradictory voices and romantic hero identities

Two further case studies illustrate how young men appeared to vacillate between 'stereotypical' and gender-equal attitudes to women. The stance taken seemed to depend on whether they were discussing women in general (associated with normative attitudes), a specific girlfriend or romantic relationship expectations (both associated with shifting attitudes). In the narratives they offered, the young men appeared to move relatively easily between these two stances, often resulting in contradictory voices. These two case studies were also selected because the young men's narratives 
Maxwell, C. (2007) “Alternative' narratives of young people's heterosexual experiences in the UK', Sexualities, 10(5): 539-558.

exemplified one further interesting dimension of masculinity, namely the cultivation of a form of romantic heroism (Redman 2001) not linked to socio-economic status. Both Jesse and Darrell actively set themselves apart from their peers and described how women were more attracted to them because they were more in touch with their 'emotions' (Darrell). Finally, the two young men presented below illustrate the point made previously in Sarah's case study that earlier negative experiences can be converted into something positive or an alternative narrative.

Jesse and Darrell, while both interviewed at the young offenders' institution, came from different socio-economic backgrounds. Jesse had spent a significant proportion of his youth in prison, had been abused by one of his parents, and it appeared, had been living without adult supervision since the age of 12 years. Darrell, on the other hand, was in the young offending system for the first time, serving a relatively short sentence. He had been brought up by his mother, until she died of cancer in his early teens, and he described a loving home environment. Since his mother's death, Darrell had been living with his father and step-mother, and mentioned on a number of occasions the close bond he had formed with his two, older step-siblings. Both Jesse and Darrell seemed to really enjoy the interview experience. This was perhaps due to the fact that many of the young men at the young offenders' institution received little or no one-to-one attention, spending most of their days either locked in their cells or in group activities. The interview seemed to provide a space for the young men to talk about themselves for over an hour, and to reminisce about the past or discuss aspirations for the future without the constant peer pressure to prove themselves to be 'men', which they described experiencing in both their current environment as well as 'back outside' (Darrell). 
Maxwell, C. (2007) “Alternative' narratives of young people's heterosexual experiences in the UK', Sexualities, 10(5): 539-558.

Despite differences in gender, ethnicity and social location between the interviewer and the two young men, the main influence on the interview interaction seemed to stem from the gender dynamic. This was particularly strong in Jesse's case because he overtly flirted with the interviewer and asked personal questions about her own relationships and sexual preferences. At one point, for instance, Jesse tried to demonstrate his technique for attracting women when he was out at a club, by asking the interviewer to role-play a woman he might be flirting with while he acted out how he would approach her and what he would say.

Jesse was 18 years-old at the time of the interview. The main relationship he discussed was with the mother of his two children. They had been together for four years and he prided himself on having helped her move from being a 'scared little girl, to a fully developed women that wanted sex you know every day'. Jesse generally portrayed himself as better than other men, both in terms of his caring and supportive skills (directly in relation to his girlfriend), but also in terms of his attractiveness to women, general sexual prowess and physical strength (the latter illustrated by stories of his boxing achievements). He believed his success with women derived from his emotional repertoire gleaned from having to grow up when he had had to leave his mother's care at age 12 because she had been sexually abusing him. He said he had 'an older brain', which meant that older women 'could relate' to him. Jesse would veer between describing himself using very traditional gender attributes (illustrated here: 'I know that when I sit and chat to a woman...she will crack [want me]') to discussing his commitment to his current girlfriend, or how he valued non-traditional female attributes: 'I respect women a lot...women who can say to men, I want this, but I don't want you to do it like this'. 
Maxwell, C. (2007) “Alternative' narratives of young people's heterosexual experiences in the UK', Sexualities, 10(5): 539-558.

Darrell was aged 17 at the time of the interview. He was the most articulate of the young men from the group sampled at the young offenders' institution and supported accommodation unit. His narrative was almost continuous, and he used the interview as an opportunity to recount the incident that had led to his imprisonment, to reminisce on a few past relationships, and to discuss in some detail his educational and career plans for the future. Like Jesse, he portrayed himself as someone who had 'always got a lot of female attention'. However, half-way through the interview Darrell 'admitted' that while he 'had [had] so many relationships...I think I've had in my life to be honest with you - three sexual experiences, three or four, where I have actually had sexual intercourse'. This was surprising given the importance that heterosexual interactions seemed to hold in his life, his stated sexual attractiveness to women, and the number of different young women he discussed during his narrative. His attitude to women, was on the one hand stereotypical ('[women] always want everything to be precise and accurate, and just perfect' or 'it's always been this natural gender thing that females are more emotional than males'), but also often non-traditional:

With females I find that I actually always act myself, maybe not as much as sometimes as I want...but with certain females, especially a couple of them I have acted like myself most of the time...I find it easier to talk to them about certain sensitive issues, whereas when I talk to adult males I'll explain something to them, and they are either afraid to show exactly what they feel about something or, they just ohhhh, like that, and forget what you just said. 
Maxwell, C. (2007) “Alternative' narratives of young people's heterosexual experiences in the UK', Sexualities, 10(5): 539-558.

A further contradiction highlighted during Darrell's narrative, which illustrated how non-traditional aspirations and emotions continued to remain embedded in more traditional comments, appeared when he discussed his future plans following his release from prison. He confidently described completing his GCE 'A' Levels, training to be an audio engineer, finding a 'special person' to settle down with, and dismissed sex outside of such a relationship context as 'worthless'. However, a few sentences later he added that because he had 'lost self-confidence in myself...it would be hard for me to fight temptation [when I'm] back outside [at the first] opportunity you get [to have sex] with somebody [else]'.

Darrell and Jesse mirrored many young men's narratives in that they assessed gender attributes and roles differently depending on the aspect of sexual and intimate relationships they were discussing. A further interesting point was that these two young men, along with a few others, attempted to actively distance themselves from their peers, describing themselves as 'mature' (Darrell) and independent, yet admired by other men, mainly because of their sexual prowess and attractiveness to women. They admitted to vulnerabilities (Darrell's grief at his mother's death some years prior due to cancer and his loss of self-confidence following his imprisonment; Jesse's experience of sexual abuse by his mother and his devastation at his girlfriend's recent unfaithfulness), but actively transformed these into qualities that made them undeniably attractive to women.

Such an identity portrayal seemed similar to Redman's (2001) 'romantic heroes'. While Redman linked these 'romantic hero' identities to 'middle-class or professional forms of cultural and economic capital' (Redman, 2001: 193), Jesse and Darrell were not from professional or middle to high socio-economic backgrounds, yet 
Maxwell, C. (2007) “Alternative' narratives of young people's heterosexual experiences in the UK', Sexualities, 10(5): 539-558.

they too used the image of a 'romantic hero' as a way of differentiating themselves from their peers and the current 'hegemonic masculinity' norm. However, as Redman (2001) argued, such a process, instead of being seen as a move away from adherence to traditional gender attributes, could actually be interpreted as being a process of integrating masculine traits such as competitiveness and autonomy into their male identity formation, while also attempting to incorporate their emotional vulnerabilities and previous life experiences firmly within a traditional gender role model.

\section{Summary and conclusion}

In this study, young people, occupying different social locations, on the whole displayed similar 'traditional' gender role attitudes, while at the same time generally espousing non-traditional romantic relationship expectations. Four key themes emerged from young people's narratives. First, there seemed to be an important disjunction between relationship expectations aspired to, and actual relationship experiences. Second, young men seemed to move relatively seamlessly between drawing on normative gender role expectations to expressing support for more gender-equal attributes during their narratives. Third, many young women experienced sexual pleasure and sexual pressure within the same relationship. The young women who experienced such a tension between pleasure and pressure experiences seemed to draw on an 'alternative' framework for describing the former but on a more traditional model of heterosexual interactions when recounting (and justifying) the situations in which they had felt pressured. Finally, a minority of young men in the study made reference to relatively 
Maxwell, C. (2007) “Alternative' narratives of young people's heterosexual experiences in the UK', Sexualities, 10(5): 539-558.

traditional gender attributes (being better than other men, being strong, being attractive to women) in defining their heterosexual identities, while at the same time also drawing on more non-traditional attributes (such as being connected to their emotions and not being afraid to show them, and being interested in providing support to others).

These findings of young people's movement between different expressions of gender roles, sexual relationship expectations, and heterosexual experiences build on previous studies that have identified the emergence of 'alternative' (Jackson and Cram, 2003), 'transitional' (Stewart, 1999), 'resistant' (Allen, 2005) discourses of sexuality, through an in depth analysis across the various dimensions of sexual relationships. As with other studies, the extent of any shift observed in young people's heterosexual identities and practices is tempered by the presence of normative gender role attitudes within young people's narratives and the manner in which these underpin the way they make sense of their experiences (Schippers, 2000; Jackson and Cram, 2003; Wilkins, 2004; Allen, 2005). Sarah, for instance, wanted to have occasional sex for pleasure, yet time after time described experiences of acquiescing to unwanted sex because she felt she had led someone on and therefore had reneged on her ability to consent. It would appear that few non-traditional attitudes to sexual relationships expressed by young people were successfully translated into practice or maintained in real life.

The second aim of this paper was to explore which contextual and structural factors might facilitate the expression of 'alternative' heterosexual identities and practices. Young people's narratives reported on in this study suggest social location may not be as significant a factor in determining the types of discourses young men and women have access to, as evidenced by Jesse and Darrell's 'romantic hero' identities and numerous young women (from across the socio-economic divide) discussing 
Maxwell, C. (2007) “Alternative' narratives of young people's heterosexual experiences in the UK', Sexualities, 10(5): 539-558.

'assertive' pleasure-focused attitudes to sex. Second, prior negative experiences that could be perceived to make a young person more 'vulnerable' to poor sexual relationship outcomes (Maxwell, 2006a) appeared to be actively converted, by some of the young people in the study, into a strength. Thus, childhood sexual abuse or parental bereavement became the springboard from which they could explore and foster alternative identities.

\section{Notes}

[1] According to the 'male in the head' framework (Holland et al., 1998), young people's definitions of sex and relationships are heavily influenced by a 'maledominated, institutionalised heterosexuality' (Ramazanoglu and Holland, 2002: 117). In this model, young women defined their own needs as being synonymous with those of young men's, which led to the privileging of male sexual pleasure in heterosexual interactions. Using Foucault's concept of 'disciplinary power' (cited in Holland et al., 1998), the 'male in the head' model suggests that women 'collude' in reproducing unequal gender relations, and that both young men and women experience little agency to deviate from traditionally espoused gender roles.

[2] Connell (1995) described the concept of 'hegemonic masculinity' as the dominant form of masculinity accepted as the ideal at a certain point in time. Young men are often aware of hegemonic norms for masculinity from within their own culture, positioning themselves in relation to these when developing their own identity (Frosh et al., 2002). 
Maxwell, C. (2007) “Alternative' narratives of young people's heterosexual experiences in the UK', Sexualities, 10(5): 539-558.

\section{References}

Allen, L. (2003) 'Girls want sex, boys want love: resisting dominant discourses of (hetero)sexuality', Sexualities 6(2): 215--236.

Allen, L. (2005) Sexual Subjects - young people, sexuality and education. Basingstoke: Palgrave Macmillan.

Breakwell, G. M. and Millward, L. J. (1997) 'Sexual self-concept and sexual risktaking', Journal of Adolescence 20: 29--41.

Cornwall, A. and Lindisfarne, N. (1994) 'Dislocating masculinity: gender, power and anthropology', in A. Cornwall and N. Lindisfarne (eds) Dislocating masculinity comparative ethnographies, pp. 11--47. London: Routledge.

Connell, R. W. (1995) Masculinities. Cambridge: Polity Press.

Frosh, S., Phoenix, A. and Pattman, R. (2002) Young masculinities - understanding boys in contemporary society. Hampshire: Palgrave.

Gilligan, C. (1995) 'The centrality of relationship in psychological development: a puzzle, some evidence, and a theory', in M. Blair, J. Holland and S. Sheldon (eds) Identity and diversity - gender and the experience of education, pp. 194--208.

Clevedon: Multilingual Matters Ltd.

Harris, A., Aapola, S. and Gonick, M. (2000) 'Doing it differently: young women managing heterosexuality in Australia, Finland and Canada', Journal of Youth Studies 3(4): 373--388.

Hey, V. (1997) The company she keeps - an ethnography of girls' friendship. Buckingham: Open University Press. 
Maxwell, C. (2007) “Alternative' narratives of young people's heterosexual experiences in the UK', Sexualities, 10(5): 539-558.

Holland, J., Ramazanoglu, C., Sharpe, S. and Thomson, R. (1998) The male in the head - young people, heterosexuality and power. London: the Tufnell Press.

Hollway, W. and Jefferson, T. (2000) Doing qualitative research differently - free association, narrative and the interview method. London: Sage.

Jackson, S. M. and Cram, F. (2003) 'Disrupting the sexual double standard: young women's talk about heterosexuality', British Journal of Social Psychology 42: 113-127.

Kehily, M. J. and Pattman, R. (2006) 'Middle-class struggle? Identity-work and leisure among sixth formers in the United Kingdom', British Journal of Sociology of Education 27(1): 37--52.

Korobov, N. and Thorne, A. (2006) 'Intimacy and distancing: young men's conversations about romantic relationships', Journal of Adolescent Research 21(1): 27-55.

Lees, S. (1986) Losing Out: Sexuality and Adolescent Girls. London: Hutchinson Education.

Mac an Ghaill, M. (1994) The making of men: masculinities, sexualities and schooling. Buckingham: Open University Press.

Maxwell, C. (2006a) 'Understanding young women's sexual relationship experiences: the nature and role of vulnerability', Journal of Youth Studies 9(2): 141--158.

Maxwell, C. (2006b) 'Context and 'contextualisation' in sex and relationships education', Health Education 106(6).

Neuman, W. L. (2000) Social Research Methods: qualitative and quantitative approaches. Boston: Allyn and Bacon. 
Maxwell, C. (2007) “Alternative' narratives of young people's heterosexual experiences in the UK', Sexualities, 10(5): 539-558.

O'Donnell, M. and Sharpe, S. (2000) Uncertain masculinities - youth, ethnicity and class in contemporary Britain. London: Routledge.

Ortiz-Torres, B., Williams, S. P. and Ehrhardt, A. A. (2003) 'Urban women's gender scripts: implications for HIV prevention', Culture, Health and Sexuality 5(1): 1--17. Ramazanoglu, C. and Holland, J. (2002) Feminist methodology - challenges and choices. London: Sage.

Redman, P. (2001) 'The discipline of love', Men and Masculinities 4(2): 186--200.

Schippers, M. (2000) 'The social organisation of sexuality and gender in alternative hard rock: an analysis of intersectionality', Gender and Society 14(6): 747--764.

Seal, D. W. and Ehrhardt, A. A. (2003) 'Masculinity and urban men: perceived scripts for courtship, romantic, and sexual interactions with women, Culture, Health and Sexuality 5(4): 293--319.

Shefer, T. and Foster, D. (2001) 'Discourses on women's (hetero)sexuality and desire in a South African local context', Culture, Health and Sexuality 3(4): 375--390.

Stewart, F. J. (1999) 'Femininities in flux? Young women, heterosexuality and (safe) sex', Sexualities 2(3): 275-290.

The London Feminist Salon Collective (2004) 'The problematization of agency in postmodern theory: as feminist educational researchers, where do we go from here?', Gender and Education 16(1): 25--33.

Thomson, R. (2000) 'Dream on: the logic of sexual practice', Journal of Youth Studies 3(4): 407--427.

Tolman, D. L., Spencer, R., Harmon, T., Rosen-Reynoso, M. and Striepe, M. (2004) 'Getting close, staying cool: early adolescent boys' experiences with romantic 
Maxwell, C. (2007) “Alternative' narratives of young people's heterosexual experiences in the UK', Sexualities, 10(5): 539-558.

relationships', in N. Way and J. Y. Chu (eds) Adolescent boys: explaining diverse cultures of boyhood, pp. 235--255. New York: New York University Press.

Walker, B. M. and Kushner, S. (1999) 'The building site: an educational approach to masculine identity', Journal of Youth Studies 2(1): 45--58.

Walkerdine, V., Lucey, H. and Melody, J. (2001) Growing up girl: psychosocial explorations of gender and class. Basingstoke: Palgrave.

Weekes, D. (2002) 'Get your freak on: how black girls sexualise identity', Sex Education 2(3): 251--262.

Wetherell, M. and Edley, N. (1999) 'Negotiating hegemonic masculinity: imaginary positions and psycho-discursive practices', Feminism and Psychology 9(3): 335--356.

Wight, D. (1999) 'Cultural factors in young heterosexual men's perception of HIV risk', Sociology of Health and Illness 21(6): 735--758.

Wight, D. and West, P. (1999) 'Poor recall, misunderstandings and embarrassment: interpreting discrepancies in young men's reported heterosexual behaviour', Culture, Health and Sexuality 1(1): 55--78.

Wilkins, A. C. (2004) "'So full of myself as a chick" - Goth women, sexual independence, and gender egalitarianism', Gender and Society 18(3): 328--349.

Youdell, D. (2004) 'Wounds and Reinscriptions: schools, sexualities and performative subjects', Discourses: studies in the cultural politics of education 25(4): 477--493.

Youdell, D. (2005) 'Sex-gender-sexuality: how sex, gender and sexuality constellations are constituted in secondary schools', Gender and Education 17(3): 249--270. 
Maxwell, C. (2007) “Alternative' narratives of young people's heterosexual experiences in the UK', Sexualities, 10(5): 539-558.

\section{Biographical Note}

Claire Maxwell is a Research Officer at the Thomas Coram Research Unit, Institute of Education, University of London. Her research interests include young people's experiences of intimate and sexual relationships, sex education, sexual coercion, young women and agency, international sexual health promotion initiatives.

Address: Thomas Coram Research Unit, Institute of Education, University of London, 27/28 Woburn Square, London, WC1H 0AA, UK. [telephone: 0207612 6957; e-mail: c.maxwell@ioe.ac.uk]

\section{Acknowledgements}

I would like to thank Peter Aggleton and Kate Wood, as well as the two anonymous reviewers, all of whom provided very useful suggestions on ways to improve the paper. 
Maxwell, C. (2007) “Alternative' narratives of young people's heterosexual experiences in the UK', Sexualities, 10(5): 539-558.

\section{Contact details for the next six months}

Claire Maxwell, Thomas Coram Research Unit, Institute of Education, University of London, 27/28 Woburn Square, London, WC1H 0AA, UK.

Telephone: 02076126957

E-mail: c.maxwell@ioe.ac.uk 